\title{
Antioxidant Properties and Fatty Acid Profile of Cretan Extra Virgin Bioolive Oils: A Pilot Study
}

\author{
Dariusz Nowak (D), Michał Gośliński, and Cezary Popławski \\ Department of Nutrition and Dietetics, Faculty of Health Sciences, Ludwik Rydygier Collegium Medicum in Bydgoszcz, \\ Nicolaus Copernicus University in Toruń, Dębowa 3, 85-626 Bydgoszcz, Poland \\ Correspondence should be addressed to Dariusz Nowak; d.nowak@cm.umk.pl
}

Received 17 February 2021; Revised 18 March 2021; Accepted 19 March 2021; Published 26 March 2021

Academic Editor: Eduard Hernández

Copyright ( 2021 Dariusz Nowak et al. This is an open access article distributed under the Creative Commons Attribution License, which permits unrestricted use, distribution, and reproduction in any medium, provided the original work is properly cited.

\begin{abstract}
Olive oil is considered a valuable ingredient of human diet. It is a good source of mono- and polyunsaturated fatty acids, as well as other bioactive compounds, especially polyphenols. The composition of olive oil depends mainly on the variety of plant, cultivation practices, and manufacturing conditions. Traditional processing methods may ensure better quality and health benefits. Therefore, the aim of the study was the evaluation of antioxidant properties and fatty acid profile of Cretan extra virgin bioolive oils. These ones were compared with commercial Spanish, Italian, and Greek extra virgin olive oils. Obtained results showed that sample Cretan 1 had about 15\% higher antioxidant capacity and about 60\% higher total polyphenol content than commercial counterparts. This one had also a favorable profile of fatty acids, especially $20 \%$ more linoleic acid. We concluded that traditional production methods, using millstones, cold pressing, and without centrifugation and filtration ensure better olive oil quality and related health benefits.
\end{abstract}

\section{Introduction}

Olive oil is a popular source of fats in the human diet, especially in the Mediterranean diet. In general, olive oil is characterized by high amounts of monounsaturated fatty acid (MUFA) and contains minor components with biological properties (e.g., phenolic compounds, pigments, squalene, sitosterols, and triterpenes) [1]. A specific composition of olive oil fatty acids and other bioactive compounds, such as polyphenols, has been proven to be protective against the development of cardiovascular diseases [2-5]. The content of these components depends on the cultivar, climate, harvesting time, and the manufacturing conditions $[1,6]$.

According to the European Union legislation, olive oil is classified into categories reflecting its quality and organoleptic properties, namely, extra virgin olive oil (EVOO), virgin olive oil (VOO), lampante virgin olive oil (LVOO), refined olive oil (ROO), and also olive oil (OO) [7, 8]. EVOO produced by mechanically pressing the olives is considered the best quality and possesses the best composition of bioactive compounds, which affect its health benefits $[9,10]$. These olive oils contain an array of phenolic antioxidants, from three major chemical classes: the simple phenolics (tyrosol and hydroxytyrosol), the secoiridoids (oleuropein aglycon and oleocanthal), and lignans [11-13] and phenolic acids (vanillic, chlorogenic, gallic, caffeic, $p$-coumaric, and ferulic) [13].

Greece is ranked third after Spain and Italy in virgin olive oil production. In Greece and Italy, the extra virgin olive oil is consumed in majority, whereas in Spain, this represents less than half. The dominant olive cultivar in Greece is the cv. Koroneiki, especially on Crete. This gives oils of medium to high content of phenolic compounds. Greek extra virgin bioolive oils, produced mainly with traditional, nonintensive cultivation practices, are mostly of exceptional quality [14, 15]. Recent study shows that Greek EVOO had a high content of oleocanthal and oleacein and their derivatives [12]. These compounds are considered key oxidation inhibitors. It is worthy to note that oleacein has been declared a more potent antioxidant than hydroxytyrosol [16, 17]. A study showed that the specific phenolic content within EVOO can affect human health $[18,19]$. Literature data for Greek, especially Cretan extra virgin olive oils, are not as popular 
as those for Spanish or Italian ones. Therefore, the aim of the study was the evaluation of antioxidant properties and the fatty acid profile of Cretan extra virgin bioolive oils. These ones were compared with commercial Spanish, Italian, and Greek extra virgin olive oils.

\section{Materials and Methods}

2.1. Materials. The analysis comprised five extra virgin olive oils. Spanish, Italian, and Greek samples were purchased at a local health food store and declared as extra virgin. Cretan extra virgin bioolive oils were produced from cv. Koroneiki (Chania region, northwest Crete) and have been certificated by BIO HELLAS no. B-515504 (Cretan 1) and no. B-515573 (Cretan 2). Moreover, sample Cretan 1 comes from two hundred years of organic cultivation (i.e., manual harvesting, without artificial irrigation), and this olive oil was produced by a traditional method using millstones, cold pressing, and without centrifugation and filtration. All the analyzed olive oils were produced between April and May 2018 (bottled into $250 \mathrm{~mL}$ ) and had at least one-year best-before date.

2.2. Methods. For the spectrophotometric assays, $1 \pm 0.01 \mathrm{~g}$ of olive oil was extracted with $9.3 \mathrm{~mL}$ n-hexane and homogenized using a vortex mixer for $30 \mathrm{sec}$. For each olive oil, five parallel samples in three replicates were prepared.

2.3. DPPH Assay. The antioxidant capacity of the olive oils was determined in extracts ( $1 \mathrm{~g}$ of olive oil and $9.3 \mathrm{~mL} \mathrm{n}$-hexane) by a standard DPPH method using $0.1 \mathrm{mM}$ methanol solution of a 1,1-diphenyl-2-picrylhydrazyl (DPPH, Sigma-Aldrich) [20]. This method is widely used to test the antioxidant capacity of foods, including olive oils [21]. The absorbance was measured on a Hitachi U-1900 spectrophotometer at $517 \mathrm{~nm}$ after $30 \mathrm{~min}$ of incubation in the dark at room temperature. For each olive oil, five parallel samples in three replicates were analyzed, from which the mean value was calculated. The antioxidant capacity was expressed as milligrams of Trolox per 1 liter of olive oil (mg Tx/L).

2.4. ABTS Assay. The antioxidant capacity of the olive oils was determined by Re et al.'s [22] method using 2,2' -azinobis-(3-ethyl-benzothiazoline-6-sulfonic acid) diammonium salt (ABTS, Sigma-Aldrich). The absorbance was measured on a Hitachi U-1900 spectrophotometer at $734 \mathrm{~nm}$ after $6 \mathrm{~min}$ of incubation in the dark at room temperature. For each olive oil, five parallel samples in three replicates were analyzed, from which the mean value was calculated. The antioxidant capacity was expressed as milligrams of Trolox per 1 liter of olive oil (mg Tx/L).

2.5. Folin-Ciocalteu Assay. The total polyphenols content (TP) of the samples was determined by the Folin-Ciocalteu assay [23]. The absorbance was measured on a Hitachi U1900 spectrophotometer at $765 \mathrm{~nm}$ after $30 \mathrm{~min}$ incubation in the dark at room temperature. The results were expressed as milligrams of gallic acid equivalents per 1 liter of olive oil (mg GAE/L).
2.6. Determination of Fatty Acid Profile. The fatty acid profile was analyzed according to the European Union Commission Regulation [24] using a Hewlett-Packard 6890 gas chromatograph, equipped with a flame-ionization detector (FID) and a SP-2560 fused silica capillary column $(100 \mathrm{~m} \times 0.25 \mathrm{~mm}$; $0.20 \mu \mathrm{m}$ film thickness). The injector and detector temperatures were set at $220^{\circ} \mathrm{C}$ and $240^{\circ} \mathrm{C}$, respectively. Helium was used as a carrier gas with a flow rate of $1 \mathrm{~mL} \mathrm{~min}^{-1}$. The analysis was performed at the following temperature program: $140^{\circ} \mathrm{C}$ held for $5 \mathrm{~min}$, then increased at rate of $4^{\circ} \mathrm{C} / \mathrm{min}$ to $240^{\circ} \mathrm{C}$, and held for the subsequent $20 \mathrm{~min}$. The total run time was approximately $50 \mathrm{~min}$. Individual fatty acids were identified by comparing their retention times with standards and quantified as a percentage of the total fatty acids.

2.7. Statistical Analysis. The results were statistically analyzed by calculating the mean and standard deviation. The interpretation of the results was performed with MS Excel 2010 Analysis ToolPak software, with one-way analysis of variance (ANOVA) using Tukey's as a posttest: different letters in the same row indicate statistical significance (at $p<0.05$ ).

\section{Results and Discussion}

3.1. Antioxidant Properties. Obtained results showed that among all the analyzed olive oils, the significantly highest antioxidant capacity, both the DPPH and ABTS assays, was determined in sample Cretan 1, i.e., $348 \pm 5.0$ and $623 \pm 7.0$ mg Tx/L, respectively (Table 1 ). Olive oil Cretan 1 had also the highest total polyphenol content $(658 \pm 40 \mathrm{mg} \mathrm{GAE} / \mathrm{L})$. Other extra virgin olive oils were characterized by TP about $400 \mathrm{mg}$ GAE/L, with no significant differences between them $(p<0.05)$. The sample Cretan 2 was similar in antioxidant capacity to commercial Greek and Italian olive oils, but their values were slightly lower than the Spanish one.

Other researchers reported a great variability in TP ranged from 50 to $1000 \mathrm{mg} / \mathrm{kg}$ (usually $100-300 \mathrm{mg} / \mathrm{kg}$ ) in olive oils of different origin, i.e., Greek, Italian, Spanish, Israeli, and Turkish $[14,25,26]$. Total polyphenol content has been repeatedly proved to be a marker for olive oil stability, which is also related to characteristic taste. Moreover, TP was considered a parameter which categorized olive oils as low (50-200 mg GAE/kg), medium (200-500 mg GAE/kg), and high (500-1000 mg GAE/kg) [14]. In addition, literature data stated that cv. Koroneiki gives olive oils of higher TP content, in general [27]. In another study, fifty-five monoor multivarietal extra virgin olive oils from Italy, Spain, France, Turkey, Greece, Portugal, Australia, the USA, and South Africa were analyzed. The oil samples produced from Italian cv. Coratina possessed the highest amount of polyphenols and antioxidant capacity, whilst the sample produced from French cv. Cayon contained the lowest amount. Among the analyzed olive oils was also some Cretan of cv. Koroneiki, of which its antioxidant properties were average in relation to the others [28]. Moreover, Sicari [29] determined the antioxidant capacity, TP, and structure of polyphenolic compounds in three different Italian extra virgin olive oils from the province of Reggio Calabria. The analyzed samples had a high content of polyphenols ranged 370- 
TABLe 1: Antioxidant capacity and total polyphenols of extra virgin olive oils.

\begin{tabular}{lccccc}
\hline & Spanish & Italian & Greek & Cretan 1 & Cretan 2 \\
\hline DPPH (mg Tx/L) & $324 \pm 5.0^{\mathrm{b}}$ & $313 \pm 3.0^{\mathrm{c}}$ & $290 \pm 4.0^{\mathrm{d}}$ & $348 \pm 5.0^{\mathrm{a}}$ & $282 \pm 1.0^{\mathrm{d}}$ \\
ABTS (mg Tx/L) & $552 \pm 7.0^{\mathrm{b}}$ & $513 \pm 5.0^{\mathrm{c}}$ & $501 \pm 5.0^{\mathrm{c}}$ & $623 \pm 7.0^{\mathrm{a}}$ & $517 \pm 6.0^{\mathrm{c}}$ \\
TP $(\mathrm{mg} \mathrm{GAE} / \mathrm{L})$ & $409 \pm 36^{\mathrm{b}}$ & $393 \pm 62^{\mathrm{b}}$ & $403 \pm 86^{\mathrm{b}}$ & $658 \pm 40^{\mathrm{a}}$ & $423 \pm 14^{\mathrm{b}}$ \\
\hline
\end{tabular}

Data are mean $\pm \mathrm{SD}(n=5)$. Different letters in the same row indicate statistical significance at $p<0.05$; Tx: Trolox equivalents; GAE: gallic acid equivalents.

TABLE 2: Fatty acid profile of extra virgin olive oils (\%).

\begin{tabular}{|c|c|c|c|c|c|}
\hline & Spanish & Italian & Greek & Cretan 1 & Cretan 2 \\
\hline Caprylic acid C8:0 & nd & nd & nd & nd & nd \\
\hline Capric acid $\mathrm{C} 10: 0$ & nd & nd & nd & nd & nd \\
\hline Lauric acid C12:0 & $0.03 \pm 0.04$ & nd & nd & nd & nd \\
\hline Tridecanoic acid C13:0 & nd & nd & nd & nd & nd \\
\hline Myristic C14:0 & nd & nd & nd & nd & nd \\
\hline Myristoleic acid C14: 1 & nd & nd & nd & nd & nd \\
\hline Pentadecanoic acid C15:0 & nd & nd & nd & nd & nd \\
\hline Palmitic acid C16:0 & $13.08 \pm 0.55$ & $12.98 \pm 0.08$ & $12.93 \pm 0.16$ & $13.20 \pm 0.25$ & $12.94 \pm 0.14$ \\
\hline Palmitoleic acid C16: 1 & $1.05 \pm 0.23^{\mathrm{a}}$ & $0.67 \pm 0.72^{\mathrm{ab}}$ & $0.53 \pm 0.57^{\mathrm{b}}$ & $0.12 \pm 0.02^{\mathrm{c}}$ & $0.12 \pm 0.01^{\mathrm{c}}$ \\
\hline Heptadecanoic acid C17:0 & $0.15 \pm 0.04^{\mathrm{b}}$ & $0.63 \pm 0.75^{\mathrm{a}}$ & $0.47 \pm 0.58^{\mathrm{a}}$ & $0.84 \pm 0.02^{\mathrm{a}}$ & $0.77 \pm 0.01^{\mathrm{a}}$ \\
\hline Stearic acid C18:0 & $3.25 \pm 0.02^{\mathrm{a}}$ & $2.86 \pm 0.07^{\mathrm{b}}$ & $2.76 \pm 0.06^{\mathrm{b}}$ & $2.87 \pm 0.01^{\mathrm{b}}$ & $2.91 \pm 0.03^{\mathrm{b}}$ \\
\hline Elaidic acid C18: $1 \mathrm{n} 9 \mathrm{t}$ & nd & nd & nd & nd & nd \\
\hline Oleic acid C18: $1 \mathrm{n} 9 \mathrm{c}$ & $72.77 \pm 0.14^{\mathrm{c}}$ & $73.74 \pm 0.16^{\mathrm{b}}$ & $75.29 \pm 0.01^{\mathrm{a}}$ & $72.49 \pm 1.29^{\mathrm{bc}}$ & $74.18 \pm 0.10^{\mathrm{b}}$ \\
\hline Linoleic acid C18:2 & $8.13 \pm 0.04^{\mathrm{b}}$ & $7.60 \pm 0.10^{\mathrm{c}}$ & $6.44 \pm 0.06^{\mathrm{d}}$ & $8.94 \pm 0.62^{\mathrm{a}}$ & $7.56 \pm 0.03^{\mathrm{c}}$ \\
\hline$\alpha$-Linolenic acid C18:3 & $0.76 \pm 0.04$ & $0.72 \pm 0.06$ & $0.74 \pm 0.01$ & $0.73 \pm 0.01$ & $0.72 \pm 0.01$ \\
\hline Arachidic acid C20:0 & $0.39 \pm 0.01^{c}$ & $0.48 \pm 0.11^{\mathrm{a}}$ & $0.41 \pm 0.01^{\mathrm{bc}}$ & $0.41 \pm 0.03^{\mathrm{bc}}$ & $0.44 \pm 0.01^{\mathrm{b}}$ \\
\hline 11-Eicosenoic acid C20:1 & $0.27 \pm 0.02$ & $0.27 \pm 0.01$ & $0.30 \pm 0.04$ & $0.26 \pm 0.01$ & $0.28 \pm 0.01$ \\
\hline Behenic acid C22:0 & $0.11 \pm 0.01^{\mathrm{b}}$ & $0.06 \pm 0.08^{\mathrm{c}}$ & $0.13 \pm 0.01^{\mathrm{ab}}$ & $0.14 \pm 0.01^{\mathrm{a}}$ & $0.07 \pm 0.11^{c}$ \\
\hline Erucic acid C22: 1 & nd & nd & nd & nd & nd \\
\hline MUFA (\%) & $74.09^{\mathrm{b}}$ & $74.68^{\mathrm{b}}$ & $76.12^{\mathrm{a}}$ & $72.87^{\mathrm{b}}$ & $74.58^{\mathrm{b}}$ \\
\hline PUFA (\%) & $8.89^{\mathrm{b}}$ & $8.32^{\mathrm{b}}$ & $7.18^{\mathrm{c}}$ & $9.67^{\mathrm{a}}$ & $8.28^{\mathrm{b}}$ \\
\hline SFA (\%) & 17.01 & 17.00 & 16.7 & 17.46 & 17.14 \\
\hline
\end{tabular}

Data are mean $\pm \mathrm{SD}(n=4)$. Different letters in the same row indicate statistical significance at $p<0.05$; nd: not detected; MUFA: monounsaturated fatty acids; PUFA: polyunsaturated fatty acids; SFA: saturated fatty acids.

$530 \mathrm{mg}$ GAE/kg. Moreover, in this study, a positive correlation was observed between the antioxidant activity (determined by DPPH and ABTS assay) and the concentration of total polyphenols [29]. Our results also confirmed positive correlation between the DPPH and ABTS methods $(r=0.902)$. Furthermore, the ABTS assay resulted in a much higher value of antioxidant capacity, which was also confirmed in other studies [30, 31]. De Bruno et al. [31] reported that it could be due to the different composition of analyzed samples containing hydrophilic and lipophilic antioxidant compounds. The ABTS assay is more applicable to both hydrophilic and lipophilic antioxidant systems, whereas $\mathrm{DPPH}$ assay is more related to hydrophobic system response [32]. In addition, our results showed a higher correlation between ABTS and TP $(r=0.912)$ than between DPPH and $\mathrm{TP}(r=0.738)$.

On the other hand, Condelli et al. [33] reported that the differences in antioxidant capacity may depend on the com- position and profile of phenolic compounds, rather than total polyphenol content. This study was conducted on 75 Italian commercial extra virgin olive oils. Finally, Jimenez-Lopez et al. [34] pointed out various factors that affect the quality of EVOO and its bioactive compounds. Bruno et al. [31] concluded that harvesting time and climate conditions influence the phenol composition as ratios of phenol compounds and their total amount.

3.2. Fatty Acid Profile. The appropriate profile of fatty acids determines the quality and health benefits of olive oil. The analyses showed that the tested olives had a typical content of oleic acid C18:1 (above 72\%). Particularly important for health are polyunsaturated fatty acids (PUFA). Sample Cre$\tan 1$ had about 20\% more linoleic acid C18:2, whereas the content of $\alpha$-linolenic acid C18:3 did not differ significant between all the samples (Table 2). 
The mean values of fatty acid profile found in the present study were the within limits established by the International Olive Oil Council for purity criteria of olive oils [35]. Stefanoudaki et al. [15] reported that Greek olive oils of cv. Koroneiki were characterized by a higher concentration of oleic acid C18: 1 (74.7-79.9\%), but the concentration of linoleic acid C18:2 and $\alpha$-linolenic acid C18:3 was slightly lower (ca. $5.0-7.0 \%$ and $0.55-0.76 \%$, respectively). Mikrou et al. [36] studied 68 monovarietal EVOOs, originating from three regions of Greece and two local cultivars (Koroneiki and Kolovi), and reported similar concentration oleic, linoleic, and $\alpha$-linolenic acid. The exception was the cultivar Kolovi, which had a higher linoleic acid content of $11.63 \%$ [36]. Other studies showed that Italian and Spanish olive oils had even lower values of $\mathrm{C} 18: 3$, i.e., $0.49-0.54 \%$ [37] and $0.48 \%$ [38], respectively. These values were much lower than obtained for commercial olive oils in our studies, whereas Morello et al. [39] reported similar to our values of C18:3. Taking into account the content of PUFA, the tested samples present the upper range of these compounds, which could be found in literature data. Furthermore, Stefanoudaki et al. [15] stated that lower concentration of oleic acid resulted in a higher concentration of heptadecanoic C17:0 and linoleic C18:2 acids, which was also confirmed in our research. Therefore, Kosma et al. [40] concluded that variations in the fatty acid composition may be owed to factors such as cultivar and other factors for example climatic conditions and geographical origin. The reported statement for Greek oils has been also confirmed in different studies on Italian olive oils. Moreover, Piscopo et al. [41] demonstrated the effect of olive cultivar and the environmental influences on the fatty acid composition of monovarietal olive oils, considering also the quality of a same cultivar in different areas.

We are aware that our study has some limitations. In the next studies, the profile of polyphenolic compounds and other valuable parameters such as tocopherol, squalene, oleocanthal, and oleacein should be examined.

\section{Conclusions}

The results of our research showed that the sample Cretan 1 had about $15 \%$ higher antioxidant capacity and about $60 \%$ higher total polyphenol content than Spanish, Italian, and Greek extra virgin olive oils. These olive oil had also a favorable composition of fatty acids, especially linoleic and $\alpha$-linolenic acid. The sample Cretan 2 did not differ significant from the commercial counterparts.

In conclusion, the antioxidant properties depend on the manufacturing conditions. Oils from olives grown on organic farms (manual harvesting, without artificial irrigation) and produced with traditional methods, i.e., using millstones, cold pressing, and without centrifugation and filtration, had higher antioxidant properties and favorable profile of fatty acids.

\section{Data Availability}

The results are in the article and in the corresponding author.

\section{Conflicts of Interest}

The authors declare no conflict of interest.

\section{Authors' Contributions}

D.N. is responsible for the design of experiments, experiments, data analysis, and writing of manuscript; M.G. is for the experiments and statistical analysis-support; and C.P critically revised the paper. All the authors have approved the final version of the manuscript.

\section{Acknowledgments}

We are grateful to the management of the company GUEST SI, Gliwice, Poland, for providing us with Cretan bioolive oil samples.

\section{References}

[1] M. Fito, R. de la Torre, M. Farré-Albaladejo, O. Khymenetz, J. Marrugat, and M.-I. Covas, "Bioavailability and antioxidant effects of olive oil phenolic compounds in humans: a review," Annali dell'Istituto Superiore di Sanità, vol. 43, no. 4, pp. 375-381, 2007.

[2] M. I. Covas, K. Nyyssönen, H. E. Poulsen et al., "The effect of polyphenols in olive oil on heart disease risk factors: a randomized trial," Annals of Internal Medicine, vol. 145, no. 5, pp. 333-341, 2006.

[3] EFSA, Panel on Dietetic Products, Nutrition and Allergies, "Scientific opinion on the substantiation of health claims related to polyphenols in olive oil and protection of LDL particles from oxidative damage," EFSA Journal, vol. 9, 2011.

[4] S. Martín-Peláez, M. I. Covas, M. Fitó, A. Kušar, and I. Pravst, "Health effects of olive oil polyphenols: recent advances and possibilities for the use of health claims," Molecular Nutrition \& Food Research, vol. 57, no. 5, pp. 760-771, 2013.

[5] A. Hernáez, S. Fernández-Castillejo, M. Farràs et al., "Olive oil polyphenols enhance high-density lipoprotein function in humans. A randomized controlled trial," Arteriosclerosis, Thrombosis, and Vascular Biology, vol. 34, pp. 2115-2119, 2014.

[6] E. Gimeno, A. I. Castellote, R. M. Lamuela-Raventós, M. C. de la Torre, and M. C. López-Sabater, "The effects of harvest and extraction methods on the antioxidant content (phenolics, $\alpha$ tocopherol, and $\beta$-carotene) in virgin olive oil," Food Chemistry, vol. 78, no. 2, pp. 207-211, 2002.

[7] R. Garcia, N. Martins, and M. J. Cabrita, "Putative markers of adulteration of extra virgin olive oil with refined olive oil: prospects and limitations," Food Research International, vol. 54, no. 2, pp. 2039-2044, 2013.

[8] F. Venturi, C. Sanmartin, I. Taglieri et al., "Development of phenol-enriched olive oil with phenolic compounds extracted from wastewater produced by physical refining," Nutrients, vol. 9, no. 8, p. 916, 2017.

[9] E. Ros, "Olive oil and CVD: accruing evidence of a protective effect," The British Journal of Nutrition, vol. 108, no. 11, pp. 1931-1933, 2012.

[10] M. Guasch-Ferré, F. B. Hu, M. A. Martínez-González et al., "Olive oil intake and risk of cardiovascular disease and 
mortality in the PREDIMED Study," BMC Medicine, vol. 12, p. 78, 2014.

[11] A. Bendini, L. Cerretani, A. Carrasco-Pancorbo et al., "Phenolic molecules in virgin olive oils: a survey of their sensory properties, health effects, antioxidant activity and analytical methods. An overview of the last decade," Molecules, vol. 12, no. 8, pp. 1679-1719, 2007.

[12] E. Karkoula, A. Skantzari, E. Melliou, and P. Magiatis, "Direct measurement of oleocanthal and oleacein levels in olive oil by quantitative (1)H NMR. Establishment of a new index for the characterization of extra virgin olive oils," Journal of Agricultural and Food Chemistry, vol. 60, no. 47, pp. 11696-11703, 2012.

[13] G. P. Blanch, G. Flores, M. C. Gómez-Jiménez, and M. L. Ruiz del Castillo, "Effect of the treatment of the olive tree (Olea europaea L.) on the phenolic content and antioxidant properties in olive fruits," Journal of Food and Nutrition Research, vol. 6, pp. 49-55, 2018.

[14] N. Kalogeropoulos and M. Z. Tsimidou, "Antioxidants in Greek virgin olive oils," Antioxidants, vol. 3, no. 2, pp. 387413, 2014.

[15] E. Stefanoudaki, F. Kotsifaki, and A. Koutsaftakis, "Classification of virgin olive oils of the two major Cretan cultivars based on their fatty acid composition," Journal of the American Oil Chemists' Society, vol. 76, no. 5, pp. 623-626, 1999.

[16] F. Paiva-Martins, J. Fernandes, S. Rocha et al., "Effects of olive oil polyphenols on erythrocyte oxidative damage," Molecular Nutrition \& Food Research, vol. 53, no. 5, pp. 609-616, 2009.

[17] V. Sánchez de Medina, H. Miho, E. Melliou, P. Magiatis, F. Priego-Capote, and L. de Castro, "Quantitative method for determination of oleocanthal and oleacein in virgin olive oils by liquid chromatography-tandem mass spectrometry," Talanta, vol. 162, pp. 24-31, 2017.

[18] K. Agrawal, E. Melliou, X. Li et al., "Oleocanthal-rich extra virgin olive oil demonstrates acute anti-platelet effects in healthy men in a randomized trial," Journal of Functional Foods, vol. 36, pp. 84-93, 2017.

[19] T. Nikou, V. Liaki, P. Stathopoulos et al., "Comparison survey of EVOO polyphenols and exploration of healthy aging- promoting properties of oleocanthal and oleacein," Food and Chemical Toxicology, vol. 125, pp. 403-412, 2019.

[20] G.-C. Yen and H.-Y. Chen, "Antioxidant activity of various tea extracts in relation to their antimutagenicity," Journal of Agricultural and Food Chemistry, vol. 43, no. 1, pp. 27-32, 1995.

[21] M. N. Franco, T. Galeano-Díaz, Ó. López et al., "Phenolic compounds and antioxidant capacity of virgin olive oil," Food Chemistry, vol. 163, pp. 289-298, 2014.

[22] R. Re, N. Pellegrini, A. Proteggente, A. Pannala, M. Yang, and C. Rice-Evans, "Antioxidant activity applying an improved ABTS radical cation decolorization assay," Free Radical Biology \& Medicine, vol. 26, no. 9-10, pp. 1231-1237, 1999.

[23] V. L. Singleton, R. Orthofer, and R. M. Lamuela-Raventós, "[14] Analysis of total phenols and other oxidation substrates and antioxidants by means of Folin-Ciocalteu reagent," Methods in Enzymology, vol. 299, pp. 152-178, 1999.

[24] “Commission Implementing Regulation (EU) 2015/1833 of 12 October 2015 amending Regulation (EEC) No 2568/91 on the characteristics of olive oil and olive-residue oil and on the relevant methods of analysis," http://data.europa.eu/eli/reg_ impl/2015/1833/oj.
[25] M. Tsimidou, "Polyphenols and quality of virgin olive oil in retrospect," Italian Journal of Food Science, vol. 10, pp. 99116, 1998.

[26] D. Boskou, G. Blekas, and M. Z. Tsimidou, "Phenolic compounds in olive oil and olives," Current Topics in Nutraceutical Research, vol. 3, pp. 125-136, 2005.

[27] A. Agiomyrgianaki, P. V. Petrakis, and P. Dais, "Influence of harvest year, cultivar and geographical origin on Greek extra virgin olive oils composition: a study by NMR spectroscopy and biometric analysis," Food Chemistry, vol. 135, no. 4, pp. 2561-2568, 2012.

[28] B. Bayram, T. Esatbeyoglu, N. Schulze, B. Ozcelik, J. Frank, and G. Rimbach, "Comprehensive analysis of polyphenols in 55 extra virgin olive oils by HPLC-ECD and their correlation with antioxidant activities," Plant Foods for Human Nutrition, vol. 67, no. 4, pp. 326-336, 2012.

[29] V. Sicari, "Antioxidant potential of extra virgin olive oils extracted from three different varieties cultivated in the Italian province of Reggio Calabria," Journal of Applied Botany and Food Quality, vol. 90, pp. 76-82, 2017.

[30] A. Floegel, D. O. Kim, S. J. Chung, S. I. Koo, and O. K. Chun, "Comparison of ABTS/DPPH assays to measure antioxidant capacity in popular antioxidant-rich US foods," Journal of Food Composition and Analysis, vol. 24, no. 7, pp. 10431048, 2011.

[31] A. De Bruno, R. Romeo, A. Piscopo, and M. Poiana, “Antioxidant quantification in different portions obtained during olive oil extraction process in an olive oil press mill," Journal of the Science of Food and Agriculture, vol. 101, no. 3, pp. 1119-1126, 2021.

[32] D. O. Kim, K. W. Lee, H. J. Lee, and C. Y. Lee, "Vitamin C equivalent antioxidant capacity (VCEAC) of phenolic phytochemicals," Journal of Agricultural and Food Chemistry, vol. 50, no. 13, pp. 3713-3717, 2002.

[33] N. Condelli, M. C. Caruso, F. Galgano, D. Russo, L. Milella, and F. Favati, "Prediction of the antioxidant activity of extra virgin olive oils produced in the Mediterranean area," Food Chemistry, vol. 177, pp. 233-239, 2015.

[34] C. Jimenez-Lopez, M. Carpena, C. Lourenço-Lopes et al., "Bioactive compounds and quality of extra virgin olive oil," Food, vol. 9, no. 8, p. 1014, 2020.

[35] International Olive Oil Council Trade Standard Applying to Olive Oils and Olive: Pomace Oils, IOOC, Madrid, Spain, 2008.

[36] T. Mikrou, E. Pantelidou, N. Parasyri et al., "Varietal and geographical discrimination of Greek monovarietal extra virgin olive oils based on squalene, tocopherol, and fatty acid composition," Molecules, vol. 25, no. 17, p. 3818, 2020.

[37] M. P. Aguilera, G. Beltrán, D. Ortega, A. Fernández, A. Jiménez, and M. Uceda, "Characterisation of virgin olive oil of Italian olive cultivars: 'Frantoio' and 'Leccino', grown in Andalusia," Food Chemistry, vol. 89, no. 3, pp. 387-391, 2005.

[38] E. Gimeno, K. de la Torre-Carbot, R. M. Lamuela-Raventós et al., "Changes in the phenolic content of low density lipoprotein after olive oil consumption in men. A randomized crossover controlled trial," British Journal of Nutrition, vol. 98, pp. 1243-1250, 2007.

[39] J. R. Morelló, M. J. Motilva, M. J. Tovar, and M. P. Romero, "Changes in commercial virgin olive oil (cv Arbequina) during storage, with special emphasis on the phenolic fraction," Food Chemistry, vol. 85, pp. 357-364, 2004. 
[40] I. Kosma, A. Badeka, K. Vatavali, S. Kontakos, and M. Kontominas, "Differentiation of Greek extra virgin olive oils according to cultivar based on volatile compound analysis and fatty acid composition," European Journal of Lipid Science and Technology, vol. 118, no. 6, pp. 849-861, 2016.

[41] A. Piscopo, A. Zappia, A. De Bruno, and M. Poiana, "Effect of the harvesting time on the quality of olive oils produced in Calabria," European Journal of Lipid Science and Technology, vol. 120, no. 7, p. 1700304, 2018. 